\title{
Disseminated Peritoneal Leiomyomatosis with Uterine Smooth Muscle Tumors of Uncertain Malignant Potential After Morcellator
}

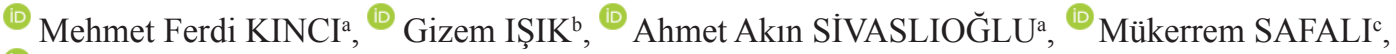 \\ ${ }^{\text {Müfit Cemal YENEN }}{ }^{\mathrm{d}}$

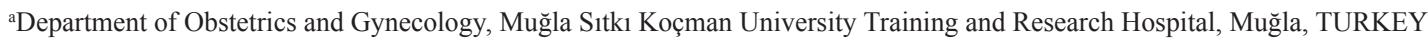 \\ ${ }^{b}$ Department of Obstetrics and Gynecology, University of Health Sciences Gülhane Training and Research Hospital, Ankara, TURKEY \\ 'Department of Pathology, University of Health Sciences Gülhane Training and Research Hospital, Ankara, TURKEY \\ dDepartment of Obstetrics and Gynecology, University of Kyrenia Faculty of Medicine, Kyrenia, TRNC
}

\begin{abstract}
Disseminated peritoneal leiomyomatosis (DPL) are characterized by the dissemination of smooth muscle nodules throughout the peritoneal surfaces. Smooth uterine muscle tumors of uncertain malignant potential (STUMP) is also a rare situation with complicated diagnosis and treatment with similar disease presentation to DPL. Interventional procedure such as laparoscopic morcellation can disseminate small tumor pieces all around the abdominal cavity. The objective of this study is to evaluate whether imminent follow-ups are needed after laparoscopic surgeries such as morcellation to reduce disease recurrence. We discuss the case of a 43-years-old patient presented with abdominal pain who had laparoscopic myomectomy 2 years ago. A uterine mass was noted with ultrasonography and computed tomography. The pathological results of masses was reported as STUMP. For both DPL and STUMP, diagnosis and treatments are difficult and problematic. This emphasizes the importance of following up with patients after laparoscopic surgeries, especially after morcellation.
\end{abstract}

Keywords: Laparoscopic myomectomy; morcellator; smooth uterine muscle tumors of uncertain malignant potential

Disseminated peritoneal leiomyomatosis (DPL) is a very rare disease; its prevalence in women of reproductive age is $<1 / 1,000,000 .{ }^{1}$ DPL is characterized by the dissemination of smooth muscle nodules throughout the peritoneal surfaces. ${ }^{2}$ It is often asymptomatic and is usually diagnosed during cesarean section surgeries because the nodules are increased by hormonal changes during pregnancy. ${ }^{3}$ DPL is typically seen in patients who have had surgery for uterine fibroids 5-10 years prior, especially surgery involving the use of laparoscopic morcellators. ${ }^{4}$ The initial diagnosis of DPL can be difficult, and the physician must rule out differential diagnoses as abdominal malignancies or metastatic leiomyosarcoma. ${ }^{5}$
Smooth uterine muscle tumors of uncertain malignant potential (STUMP) is another rare condition that require interventions such as laparoscopic morcellation. STUMP was first described by Kempson in 1973 as a tumor that had a clear malignant potential clinically but did not meet all the diagnostic malignancy criteria like sorcomas. ${ }^{6}$ The symptoms of STUMP are similar to benign uterine leiomyomas, and there are no clinical features or laboratory screening tests available for STUMP; its diagnosis can only be confirmed by pathologists. ${ }^{7}$ According to the existing scientific literature, the recurrence rate for STUMP is around 8.7$10.6 \%{ }^{8}$

Correspondence: Mehmet Ferdi KINCI

Department of Obstetrics and Gynecology, Muğla Sıtkı Koçman University Training and Research Hospital, Muğla, TURKEY E-mail: drferdikinci@gmail.com

Peer review under responsibility of Journal of Clinical Obstetrics \& Gynecology.

Received: 20 Sep 2021 Accepted: 05 Dec $2021 \quad$ Available online: 10 Dec 2021 
Morcellation can disseminate small tumor pieces all around the abdominal cavity. ${ }^{9}$ This raised an essential question whether the use of morcellation to treat STUMP or leiomyomatosis increases the risk of recurrence and/or the later incidence of DPL.

\section{CASE REPORT}

We examined a 43-year-old patient who presented with complaints of abdominal pain that had lasted for 3 months. According to her medical history, she had experienced 2 pregnancies and births and had one laparoscopic myomectomy 2 years prior. The details of morcellation in laparoscopic myomectomy was not given in the reports of the patient. The pathology results of that surgery reported uterine leiomyoma with a mitotic activity of 4-5 (out of 10). At the time of our examination, the patient had no comorbidities.

Ultrasonography performed in our clinic revealed a uterine myoma of nearly $10 \mathrm{~cm}$ at the fundus of the patient's uterus. In addition, there was a perihepatic soft tissue area adjacent to the segment 7 of the patient's liver at $3 \times 2 \mathrm{~cm}$ diameters, and an $8 \times 6$ $\mathrm{cm}$ tumoral mass at the left adnexal side of her uterus. A computed tomography scan showed a $1.7 \mathrm{~cm}$ mass in the segment 6 of the patient's liver. Also, there was seen a mass at the peritoneal surfaces, and ascites at the pouch of Douglas. To rule out any differential diagnoses of malignancy, a positron emission tomography/computed tomography scan was also administered. The nodule at the right lobe of the liver had a diameter of $1.8 \times 1.7 \mathrm{~cm}$, was located at segment 6 of the liver, and appeared exophytically. It showed small amounts of 18-fluorodeoxyglucose involvement $\left(\mathrm{SUV}_{\max }: 2.2\right)$.

Given the suspicion of malignancy or DPL, we then performed open abdominal surgery on the patient. Written informed consent was obtained from the parents of the patient. The abdominal exploration revealed multiple nodules throughout the patient's abdominal peritonea, as well as uterine myomas (Figure 1). During the operation, we performed a total abdominal hysterectomy, a bilateral salpingo- oophorectomy, and an appendectomy, and also excised multiple disseminated nodules. Pathologists subsequently examined frozen sections of the uterus and reported a smooth muscle tumor of indeterminate malignant potential but could not rule out a low-grade leiomyosarcoma. There were smooth muscle lesions involving focal celiac areas and typical focal middle atypia, with mitosis at a rate of 7-8 Mitotic Index/10 high power field (HPF) and no observed necrosis, leading to a diagnosis of STUMP (Figure 2). The other nodules around the peritoneal surface and over the omentum, intestine, liver, bladder, subdiaphragmatic surface, and appendix were determined to be smooth muscle tumors (leiomyomatosis) in the focal cellular area with low mitotic activity (3-4 Mitotic Figures/10 HPF) and no necrosis. No additional treatment was required after the surgery.

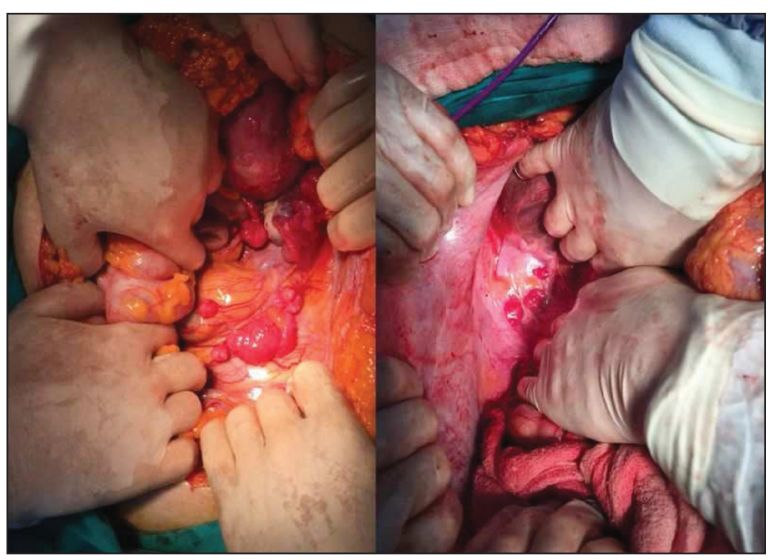

FIGURE 1: Multiple nodules throughout the abdominal peritonea

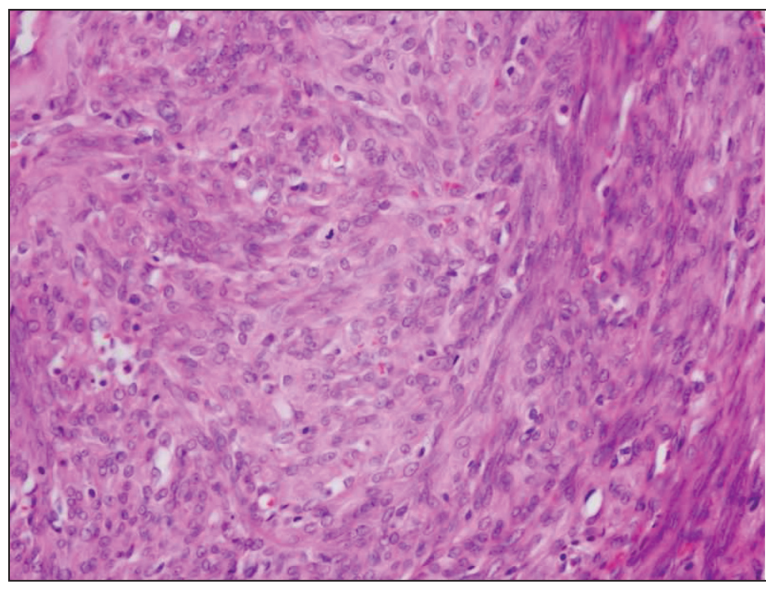

FIGURE 2: Smooth muscle lesion with mild atypia and mitosis (H\&E, x200). 


\section{DISCUSSION}

It is difficult to determine the certain etiology of DPL because it is such a rare condition. Some theories hold that it may be due to hormonal changes, while others suggest that it is caused by subperitoneal mesenchymal stem cells; still others hypothesize that it may be genetic..$^{10}$ Most important, however, is the suggestion that DPL may be iatrogenic due to the laparoscopic morcellation of uterine myomas. ${ }^{11}$ In the present case study, the patient's DPL seemed likely due to the iatrogenic morcellation that was performed 2 years prior. Complicating this situation, however, is the fact that although the pathology results of the previous operation reported leiomyomatosis, the definitive pathology results of the present operation reported STUMP.

The literature has reported other cases of recurrence after STUMP morcellation. Seidman et al. reported four cases of STUMP morcellation, all of which had malignant peritoneal disseminations after morcellation. ${ }^{12}$ In another study, Oduyebo et al. reported eight STUMP morcellation cases, 5 of which were determined to have malignant dissemination upon further exploration. ${ }^{13}$ Mowers et al. also reported that STUMP morcellation on re-exploration; 5 out of 6 patients had benign peritoneal masses, and none had resulted malignant dissemination. ${ }^{14}$

In the present case, the operation for benign leiomyomatosis 2 years prior seemed initially to merit a diagnosis of DPL. However, our pathology results from the uterus sections instead suggested a diagnosis of STUMP with benign nodular disseminations all around the peritoneal surfaces. Although most such cases have malignant disseminations, in this case, as with Mowers et al., all of the abdominal nodules were benign. In addition, the time to recurrence in the present case (2 years) was shorter than typically reported for DPL. ${ }^{14}$ Although the shortest time of DPL after morcellation reported in the literature is nine months, it is usually around 510 years. ${ }^{14}$ Another study found that 5 of 76 STUMP patients had recurrences between 1 and 216 months after an initial operation. ${ }^{15}$
Surgery is the recommended treatment for DPL. In the present case, we performed a total hysterectomy and excised the nodules. Since a few cases have shown that limiting hormonal exposure can decrease tumor size, we also performed a bilateral salpingooophorectomy to limit future hormonal exposure.

DPL is rarely seen, diagnosis is limited and treatment of disease is difficult. Fortunately, most STUMP and DPL cases have good prognosis. The present case adds to the existing literature showing that after morcellation of both leiomyomatosis and STUMP, malignant and benign masses can be seen all around the abdominal peritoneal surfaces. This emphasizes the importance of following-up with patients after laparoscopic surgeries and especially after morcellation.

In conclusion, more clinical cases are needed to determine the optimal diagnosis and treatment of these diseases and its connection to laparoscopic morcellation.

\section{Source of Finance}

During this study, no financial or spiritual support was received neither from any pharmaceutical company that has a direct connection with the research subject, nor from a company that provides or produces medical instruments and materials which may negatively affect the evaluation process of this study.

\section{Conflict of Interest}

No conflicts of interest between the authors and / or family members of the scientific and medical committee members or members of the potential conflicts of interest, counseling, expertise, working conditions, share holding and similar situations in any firm.

\section{Authorship Contributions}

Idea/Concept: Müfit Cemal Yenen, Mükerrem Safall; Design: Mehmet Ferdi Kıncl, Gizem Işılk; Control/Supervision: Müfit Cemal Yenen, Ahmet Akın Sivasloğlu; Data Collection and/or Processing: Gizem Işılk, Mehmet Ferdi Kıncl; Analysis and/or Interpretation: Ahmet Akın Sivasloğlu, Mükerrem Safall; Literature Review: Gizem Işlk, Mehmet Ferdi Kıncl; Writing the Article: Gizem Işık, Mehmet Ferdi Kıncl; Critical Review: Ahmet Akın Sivaslıoğlu, Mükerrem Safalı, Müfit Cemal Yenen; References and Fundings: Gizem Işık, Mükerrem Safall; Materials: Müfit Cemal Yenen, Mükerrem Safal. 
1. Paul PG, Naik S. Disseminated leiomyomatosis peritonei. Incidental finding in laparoscopy: a case report. Surg Laparosc Endosc Percutan Tech. 2010;20(3):e123-4. [Crossref] [PubMed]

2. Gaichies L, Fabre-Monplaisir L, Fauvet R, Alves A, Mulliri A. Leiomyomatosis peritonealisis disseminata: Two unusual cases with literature review. J Gynecol Obstet Hum Reprod. 2018;47(2):89-94. [Crossref] [PubMed]

3. Wu C, Zhang X, Tao X, Ding J, Hua K. Leiomyomatosis peritonealis disseminata: A case report and review of the literature. Mol Clin Oncol. 2016;4(6):957-8. [Crossref] [PubMed] [PMC]

4. Rosenbaum L. N-of-1 Policymaking--Tragedy, Trade-offs, and the Demise of Morcellation. N Engl J Med. 2016;374(10):986-90. [Crossref] [PubMed]

5. Kumar S, Sharma JB, Verma D, Gupta P, Roy KK, Malhotra N. Disseminated peritoneal leiomyomatosis: an unusual complication of laparoscopic myomectomy. Arch Gynecol Obstet. 2008;278(1):93-5. [Crossref] [PubMed]

6. Tun AM, Tun NM, Zin Thein K, Naing EE, Giashuddin S, Shulimovich M. A rare concur-

\section{REFERENCES}

rence of leiomyomatosis peritonealis disse minata, leiomyosarcoma of the pelvis and leiomyomatous nodule of the liver. Case Rep Oncol Med. 2016;2016:3025432. [Crossref] [PubMed] [PMC]

7. Ip PP, Cheung AN. Pathology of uterine leiomyosarcomas and smooth muscle tumours of uncertain malignant potential. Best Pract Res Clin Obstet Gynaecol. 2011;25(6): 691-704. [Crossref] [PubMed]

8. Bell SW, Kempson RL, Hendrickson MR. Problematic uterine smooth muscle neoplasms. A clinicopathologic study of 213 cases. Am J Surg Pathol. 1994;18(6):535-58. [Crossref] [PubMed]

9. Esposito NN, Hunt JL, Bakker A, Jones MW. Analysis of allelic loss as an adjuvant tool in evaluation of malignancy in uterine smooth muscle tumors. Am J Surg Pathol. 2006;30(1):97-103. [Crossref] [PubMed]

10. George S, Barysauskas C, Serrano C, Oduyebo T, Rauh-Hain JA, Del Carmen MG, et al. Retrospective cohort study evaluating the impact of intraperitoneal morcellation on outcomes of localized uterine leiomyosarcoma. Cancer. 2014;120(20):3154-8. [Crossref] [PubMed]

11. Kurman RJ, Ronnett BM. Blaustein's Pathol- ogy of the Female Genital Tract. $6^{\text {th }}$ ed Boston: Springer New York Dodrecht Heidelberg London; 2011. [Crossref]

12. Seidman MA, Oduyebo T, Muto MG, Crum CP Nucci MR, Quade BJ. Peritoneal dissemination complicating morcellation of uterine mesenchymal neoplasms. PLoS One. 2012;7(11): e50058. [Crossref] [PubMed] [PMC]

13. Oduyebo T, Rauh-Hain AJ, Meserve EE, Seidman MA, Hinchcliff E, George S, et al. The value of re-exploration in patients with inadvertently morcellated uterine sarcoma. Gynecol Oncol. 2014;132(2):360-5. [Crossref] [PubMed]

14. Mowers EL, Skinner B, McLean K, Reynolds RK. Effects of morcellation of uterine smooth muscle tumor of uncertain malignant potential and endometrial stromal sarcoma: case series and recommendations for clinical practice. J Minim Invasive Gynecol. 2015;22(4):601-6. [Crossref] [PubMed]

15. Vilos GA, Marks J, Ettler HC, Vilos AG, Prefontaine M, Abu-Rafea B. Uterine smooth muscle tumors of uncertain malignant potential: diagnostic challenges and therapeutic dilemmas. Report of 2 cases and review of the literature. J Minim Invasive Gynecol. 2012; 19(3):288-95. [Crossref] [PubMed] 